Exploring Faultlines, Conflict, Satisfaction, and Stress in Groups of Peacekeepers

\author{
Katerina Bezrukova \\ The Wharton School \\ University of Pennsylvania \\ Philadelphia, PA 19104-6370 \\ Tel: (215) 573-5726 Fax: 215-898-0401 \\ E-mail: bezrukova@wharton.upenn.edu
}

\author{
Karen A. Jehn \\ The Wharton School \\ University of Pennsylvania \\ Philadelphia, PA 19104-6370 \\ Tel: 215-898-7722 Fax: 215-898-0401 \\ E-Mail: jehn@wharton.upenn.edu \\ Martin Euwema and Nicolien Kop \\ Utrecht University \\ Heidelberglaan 1 \\ 3584 CS Utrecht \\ The Netherlands \\ E-Mail: $\underline{\text { m.euwema@fss.uu.nl }}$
}

\begin{abstract}
We would like to thank Andre Kursansew and Azra $H$ for their comments and suggestions.
\end{abstract}

January 2002 


\title{
Exploring Faultlines, Conflict, Satisfaction, and Stress in Groups of Peacekeepers
}

\begin{abstract}
We explore group faultlines in peacekeeping troops on missions between 1995 and 1999 in Bosnia. Group faultlines are defined as hypothetical dividing lines that split a group into subgroups based on demographic characteristics (e.g. age, gender, etc.), culture, norms, work attitudes, and behavior of peacekeepers. In particular, we examine how potential faultlines become active faultlines and then result in task, relationship, and cultural conflict within a group of peacekeepers. We link these types of conflict to peacekeepers' satisfaction, perceived performance, and level of work stress. We test our hypotheses on survey data from a sample of 907 Dutch military peacekeepers $(\mathrm{Ng}=168)$. Implications for practitioners and future research directions are discussed.
\end{abstract}

Key words: group faultlines, conflict, satisfaction, performance, and work stress. 


\section{Exploring Faultlines, Conflict, Satisfaction, and Stress in Groups of Peacekeepers.}

\section{Introduction}

Ethnopolitical conflicts have been a common and bloody phenomenon in human history and still persist (O’Leary \& McGarry, 1995). Approximately 160 wars and ethnic armed conflicts have been reported in the 41 years from 1945 to 1986 alone, with 22 million deaths and three times as many injured (UNICEF, 1986). Violence and ethnic tensions have more recently appeared in various forms and degrees across regions of economic poverty and underdevelopment (e.g. Chechnya, Burundi, Rwanda, and Yugoslavia). Since these problems have failed to be resolved domestically, international organizations have been actively sought to inhibit the reoccurrence of these violent conflicts. Their common protocol of resolving ethnic conflicts is to deploy peacekeeping groups to areas of ethno-political violence. The classical conception of peacekeeping incorporates a military force intervening between two conflicting parties who have agreed a cease-fire (Leeds 2001). Given the severity, urgency, and social need for successful intervention through third party mediators, the focus of this paper is to examine the peacekeeping groups on mission in Yugoslavia.

The Socialist Federal Republic of Yugoslavia (1945-91) was a federation of six republics: Slovenia, Croatia, Bosnia and Herzegovina, Serbia (with two autonomous regions Kosovo and Vojvodina), Montenegro, and Macedonia. After the death of the president of Yugoslavia, Josip Broz Tito, who led the country between 1945 and 1980, the tension between the republics increased, concluding in the declaration of independence by Slovenia and Croatia in June of 1991. The war in Yugoslavia broke out immediately thereafter, folding along the ethnic and religious lines that already existed. For presentation purposes, we provide demographic details of the ethnic makeup of Yugoslavia in 1980: $36 \%$ of the population was Serb, 19\%Croats, 8\% Slavic Muslims, 
7\% Slovenes, 7\% Albanians, 6\% Macedonians, 2\% Montenegrins, $1 \%$ Hungarians, 5\% Yugoslavs $^{1}$ and the rest $4 \%$ were others (Friedman 1980:30).

In this paper, we focus on peacekeeping troops located in Bosnia between 1995 and 1999. To provide an appropriate context in which they were operating, we offer some background information and demographic details specifically on Bosnia. Bosnia and Herzegovina was a multiethnic republic that included Bosnian Muslims 43\%, Bosnian Serbs 31\%, Bosnian Croats 17\%, and several minority groups 7\% (Golubic and Campbell 1992:8). In order to avoid being absorbed into the rest of Serb dominated Yugoslavia, Bosnia and Herzegovina followed the example of Slovenia and Croatia and declared independence in March of 1992. The Bosnian war started in April of that year. Croatia, Slovenia, and Bosnia and Herzegovina were accepted to the United Nations in May of 1992, while Macedonia, which declared independence in September, was accepted to the United Nations in April of 1993. The republics of Serbia and Montenegro that remained in Yugoslavia refer to themselves as Yugoslavia today. The war in Bosnia lasted for 3.5 years, during which period 150,000 to 200,000 Bosnians lost their lives and around $1,000,000$ refugees fled the country (Stiglmayer 1994:25). The others were besieged in the cities (so called 'safe havens') for years (Gorazde, Srebrenica, Bihac, Sarajevo, and Tuzla) and constantly bombed from the surrounding hills.

These were the issues peacekeeping groups faced when they were deployed to Bosnia. In this context of poverty, hatred, and desperation, their objective was to oversee that signed agreements between warring parties were met. The members of these groups were Dutch soldiers, ranking from corporal and sergeant to military police, from lieutenant to general. Based on social psychology and group processes theories, the peacekeeping groups were actual workgroups because they interacted daily and were task interdependent, identified each other as group members, and were seen by others as workgroups.

The focus of this paper rests solely on these peacekeeping groups. In particular, we examine the group composition of peacekeepers in its connection to different types of conflict (i.e. task, relationship, and cultural conflict), and outcomes (satisfaction,

\footnotetext{
${ }^{1}$ Many people (majority Muslims) opted for Yugoslav identity over their ethnic identity.
} 
performance, and level of job stress). We draw on social psychology and organizational behavior theories to analyze group process and outcomes in the context of political science phenomena (e.g. Komorita \& Kravitz, 1983; Lau \& Murnighan, 1998; Tajfel and Turner, 1986). Our cross-field study results in a significant number of contributions to the existing knowledge of ethno-political conflict theory and management. To the extent of our knowledge, this is one of the first papers done on peacekeeping groups with such a specific sample. Furthermore, we continue to provide empirical tests of group faultline theory and particularly, in this paper, we operationalize faultlines in terms of not only demographic characteristics (e.g. age, gender, race, etc.) as done in previous group faultline research (e.g. Thatcher, Jehn, \& Zanutto, 2002), but also norms, values, work attitudes, and behaviors of peacekeepers. Therefore, we add to the group faultline theory by taking into account more factors than just peacekeepers' demographic characteristics. We also link group processes (specifically task, relationship, and cultural conflict) to individual outcomes such as stress, satisfaction, and performance. This opens the door for some recommendations for future successful peacekeeping missions. The insights from this research can be also made applicable to negotiation, mediation, and peacekeeping training.

\section{Research Model and Hypotheses}

In this paper we explore group faultlines in peacekeeping troops on missions between 1995 and 1999 in Bosnia. Group faultlines are defined as hypothetical dividing lines that split a group into subgroups based on demographic characteristics (e.g. age, gender, etc.), culture, norms, work attitudes, and behavior of peacekeepers. We examine how potential faultlines become active faultlines and then, result in task, relationship, and cultural conflict within a group of peacekeepers. We define task conflicts as disagreements between members of two subgroups within a group around ideas and opinions about the task being performed. We define relationship conflicts as disagreements and incompatibilities between two subgroups within a group about issues that are not task related, but that focus on personal issues. Finally, we define cultural conflicts as disagreements between members of two subgroups within a group around culturally patterned features of social living. We link these types of conflict to peacekeepers' 
satisfaction, perceived performance, and level of work stress. We test our hypotheses on survey data from a sample of 907 Dutch military peacekeepers $(\mathrm{Ng}=\mathrm{XX})$.

\section{Linking Group Faultlines to Conflict}

Similar to the geological concept of faults in the Earth's crust, ethnic faultlines in groups can be inactive and go unnoticed without any changes in group processes for years (Lau and Murnighan, 1998). Although faultlines are dormant they can awake at any moment and cause the group to split along ethnic lines. While potential faultlines are based on the objective demographics of group members, active faultlines exist when the members perceive and behave as if they are two separate, different (and potentially even opposed) groups. This perception is more likely to form when potential faultlines exist and are evident in a group. Therefore, we propose that:

\section{Hypothesis 1 (H1): Groups of peacekeepers with potential ethnic faultlines are more likely to form active ethnic faultlines within the group.}

Using coalition theory (Caplow, 1956; Komorita \& Kravitz, 1983; Mack \& Snyder, 1957; Murnighan, 1978) and Schneider's attraction-selection-attrition model of organizational membership (1983), we expand group faultline theory and propose that if more demographic attributes align in the same way, group members in each subgroup will perceive the similarity within their subgroup. Since similar members are likely to interact with each other more often and find their interactions pleasant and more desirable, they will be likely to form coalitions (Byrne, 1971; Pool, 1976). Due to the similarity among group members involved in coalition formation, the conflict within subgroups is apt to decline. However, the existence of coalitions is likely to amplify the salience of ingroup/out-group membership causing strain and polarization between subgroups (Hogg, Turner, \& Davidson, 1990). Once coalitions are formed, the negative effects of stereotyping, in-group favoritism and out-group hostility are likely to sharpen the boundary salience around coalitions and strengthen conflict between them. These group processes are likely to lead to intensification of conflict between subgroups and therefore,

promote or activate intergroup conflict. In particular, we discuss and examine three types 
of conflict that have been identified in working groups, bicultural teams, and organizing entities (Amason, 1996; Jehn, 1997; Jehn and Jageuri, 2001; Jehn, Northcraft, and Neale, 1999; Pelled, 1996; Shah and Jehn, 1993).

Because of negative categorization processes, subgroups are likely to experience frustration, discomfort, hostility, and anxiety that can result in animosity and annoyance between individuals belonging to different subgroups, and hence, relationship conflict is likely to emerge between two or more subgroups (Jehn, 1997; Tajfel \& Turner, 1986). We expand Jehn's (1997) concept of relationship conflict within groups by defining relationship conflicts as disagreements and incompatibilities between two subgroups within a group about issues that are not task related, but that focus on personal issues. Furthermore, the more that demographic attributes align in the same way, the more salient the perceived similarities within subgroups, and the more salient the perceived differences between subgroups. The greater salience of these out-group differences is likely to facilitate the more intense polarization between subgroups, which will inevitably result in more fights over non-task related issues. We argue that the greater the group faultlines, the higher the level of relationship conflict between the two subgroups will be.

\section{Hypothesis 2a (H2a): The greater the group faultlines, the higher the level of relationship conflict between subgroups.}

Based on the literature on minority dissent and decision making processes in work groups, we argue that the very existence of subgroups within a group is a source of divergent thinking (De Dreu \& West, 2001). Specifically, when subgroups are formed based on alignment of group members' attributes, those members are likely to exhibit ingroup favoritism and conform to the opinion, idea, or perspective favored by their subgroup (Baron, Kerr, \& Miller, 1993). Furthermore, they are likely to have a broader range of knowledge, experience, and opinion due to intense polarization between subgroups around ideas and thoughts (e.g. Ancona \& Caldwell, 1992). This variety in knowledge and experiences can lead to disagreement among group members about group tasks (Jackson, 1992; Jehn 1995; Jehn 1997; Pelled, Eisenhardt, \& Xin, 1997). Therefore, 
we propose that this disagreement over group tasks will result in high levels of task conflict between subgroups within a group.

\section{Hypothesis 2b (H2b): The greater the group faultlines, the higher the level of task conflict between subgroups.}

Who fights about what, and how different sorts of disputes arise and get handled can also be viewed as culturally patterned features of social living (McCall, Ngeva, \& Mbebe, 1997). To predict the effect of group faultlines on cultural conflict, we draw on the literatures on coalition formation, ethnic identity, and cross-cultural research (Bacharach

\& Lawler, 1980; Phinney, 1996; Tinsley \& Pillutla, 1998). We argue that group faultlines can be formed based on the differences in beliefs, perceptions, and attitudes between different ethnic and cultural groups. This alignment along cultural lines is likely to promote affinity with one's own ethnic group and enmity toward other groups and generate coalitional activity. We, therefore, add to the coalition research by proposing that these subgroups will form based on ethnicity. Both subgroups may desire to maintain separate identities in order to preserve their unique subgroup traditions and cultures which is likely to result in cultural conflict (Deutsch, 1973). Therefore, we propose:

\section{Hypothesis 2c (H2c): The greater the group faultlines, the higher the level of cultural conflict between subgroups.}

\section{Linking Task, Relationship, and Cultural Conflicts to Satisfaction, Performance, and Stress}

Task conflict, which is focused on content-related issues, can enhance performance quality (Jehn, Northcraft, and Neale, 1999). For example, critical debate among members of two different ethnic subgroups and open discussion regarding task issues increases group performance because members are more likely to offer and evaluate various solutions, thus reaching optimal decisions and outcomes (Cosier and Rose, 1977; Schweiger, Sandberg, and Rechner, 1989; Amason, 1996). However, conflict in any form can be an uncomfortable environment, decreasing individuals' perceptions of teamwork and their satisfaction (Amason and Schweiger, 1994). When members feel discomfort 
with the group process and dissatisfaction with the group experience, they are less likely to remain together as a cohesive, cooperative group. This is likely to increase insecurity among group members and enhance uncertainty around the given task, which in turn will result in higher levels of stress.

\section{Hypotheses 3a (H3a): The higher the level of task conflict, the higher the level of peacekeepers' perceived performance.}

\section{Hypotheses 3b (H3b): The higher the level of task conflict, the lower the level of peacekeepers' satisfaction.}

\section{Hypotheses 3c (H3c): The higher the level of task conflict, the higher the level of peacekeepers' work related stress.}

Relationship conflicts frequently reported are about social events, gossip, clothing preferences, political views, and hobbies (Jehn, 1997). This type of conflict often is associated with animosity and annoyance between individuals belonging to different subgroups. These conflicts deplete energy and effort that could be expended toward task completion. Effort can be misplaced by squabbling, avoiding, or resolving the past unfairness resulting from mistreatments rather than focusing on consolidating around mutual goals. Relationship conflict can cause extreme negative process problems, which sometimes could lead to violent wars (e.g. Russian - Chechnya war). Less extreme outcomes have been reported in some organizational behavior studies. It has been shown that relationship conflict has negative effects and is responsible for outcomes such as increased turnover, high rates of absenteeism, decreased satisfaction, low levels of perceived performance, poor objective performance, and low commitment (Jehn, 1995; Jehn et al., 1997; Baron, 1991). Furthermore, when conflicts become personal, they are unproductive, hard to manage, and are likely to lead to detrimental effects such as leaving people with more negative pressure and decreasing the ability to manage the conflicts (Friedman, Tidd, Currall, \& Tsai, 2000). These detriments are likely to lead to increased stress. Empirical evidence reports that inter-personal conflict is the biggest source of stress (Motowidlo, Packard, and Manning, 1986). Therefore, we propose: 
Hypotheses 4a (H4a): The higher the level of relationship conflict, the lower the level of peacekeepers' perceived performance.

Hypotheses 4b (H4b): The higher the level of relationship conflict, the lower the level of peacekeepers' satisfaction.

Hypotheses 4c (H4c): The higher the level of relationship conflict, the higher the level of peacekeepers' job related stress.

Cultural differences increase the complexity of interactions between group members thus creating barriers of communication and understanding, increasing confusion and eventually developing confrontation between culturally different parties. Confrontation is likely to create isolation between the subgroups within a group in terms of communication and information exchanges (Hogg, Turner, \& Davidson, 1990; Murnighan, 1978). When these channels of communication and information exchange are inhibited or broken, the group does not perform at the expected productivity level, therefore resulting in lower levels of perceived performance and decreased member satisfaction (Jehn and Weldon, 1997). Furthermore, we argue that group members will experience higher levels of stress as a result of cultural conflict. Therefore, we predict that cultural conflict will lead to a lower level of perceived performance, a lower level of satisfaction and a higher level of stress.

Hypotheses 5a (H5a): The higher the level of cultural conflict, the lower the level of peacekeepers' perceived performance.

Hypotheses 5b (H5b): The higher the level of cultural conflict, the lower the level of peacekeepers' satisfaction.

Hypotheses 5c (H5c): The higher the level of cultural conflict, the higher the level of peacekeepers' job related stress. 


\section{Method and Measures}

Our data comes from a sample of Dutch military peacekeepers on missions between 1995 and 1999 in Bosnia (Nind =907, $\mathrm{Ng}=168$ ). The data was collected by Martin Euwema and Nicolein Kop, sponsored by the Clingendael Institute in 2000. The survey was sent to all officers who have been on peacekeeping missions between 1995-1999, and low ranked officers of military police as they were trained and have relatively intense contact with parties on the ground. Overall there are 907 military respondents (over 52\% response rate). Additionally, we have 70 non-military expatriates, sent to crisis areas and 50 non-Dutch military from a variety of western countries. The following paragraphs describe our measures.

Potential Faultlines. We used the peacekeepers' demographic survey data on age, gender, nationality, function (which army they serve, for example, land, air, navy, etc.), education, and tenure (years of military service). We also used the survey data on differences in culture, norms and values, work attitudes, and behaviors across peacekeepers within a group. As past research showed the importance of distinguishing between the effects of faultline strength (how cleanly a group splits into subgroups) and faultline distance (how far apart subgroups are from each other), we operationalize group faultlines in terms of faultline strength and faultline distance. We use faultline algorithm and rescaling procedure to calculate faultline strength and faultline distance scores for each work group taking into account ten characteristics listed above (Bezrukova, Jehn, \& Zanutto, 2002; Thatcher, Jehn, \& Zanutto, 2002).

Faultline Strength. This measure calculates the percent of total variation in overall group characteristics accounted for by the strongest group split, in other words, the faultline strength score indicates how a group splits cleanly into two subgroups. We have calculated the faultline strength scores excluding subgroups of size one because these subgroups cannot be considered as a group based on social psychological perspective. Possible values of faultline strength ranged from .xx (weak faultline strength) to .xx (very strong faultline strength). 
Faultline Distance. This measure calculates a distance between centroids (the Euclidean distance between the two sets of averages) and was adapted from multivariate statistical cluster analysis (e.g. Morrison, 1967; Jobson, 1992; Sharma, 1996). Possible values of faultline distance ranged from .xx (little faultline distance) to X.xx (very great faultline distance).

To rescale the variables so that they can be reasonable combined into one faultline strength and one faultline distance measure, we calculated the scores so that difference in gender $=$ difference in nationality $=$ difference of 15 years of age $($ approx $2 \mathrm{sd})=$ difference of 10 years in tenure (approx $1 \mathrm{sd}$ ) = difference of 2 units of education (approx $1 \mathrm{sd})=$ difference in function $=$ difference in culture $=$ difference in norms and values $=$ difference in work attitudes $=$ difference in behavior.

Active Faultlines. This was measured by items "How frequently did you face problems within your team" on a scale from $1=$ hardly ever to $5=$ daily; "How serious were these problems" on a scale from $1=$ not at all serious to $5=$ very serious; and "Have you been personally involved in these problems" on a scale from $1=$ not at all to $5=$ heavily involved. We also used the item "Have you made friends or good acquaintances in your team?" to indicate a subgroup formation. Additionally, the respondents were asked an open-ended question, "When people work together, it is inevitable that differences in opinion and vision, different interests and personal irritations occur. What problems in co-operation were most difficult during your last mission?" We will content analyze these text data and provide indications of active faultlines in groups of peacekeepers.

Task conflict. The peacekeepers were asked an open-ended question: "Please think about a conflict or confrontation you were involved in during your peacekeeping mission" and respond "what was this conflict about?" Additionally, task conflict was measured by the item "Was this conflict strictly a work related issue?" on a scale from $1=$ not at all to $5=$ completely.

Relationship Conflict. The peacekeepers were asked an open-ended question: "Please think about a conflict or confrontation you were involved in during your peacekeeping 
mission" and respond "what was this conflict about?" Additionally, relationship conflict was measured by the item "Was this conflict strictly a personal issue?" on a scale from $1=$ not at all to $5=$ completely.

Cultural Conflict. The peacekeepers were asked an open-ended question: "Please think about a conflict or confrontation you were involved in during your peacekeeping mission" and respond "what was this conflict about?" Additionally, cultural conflict was measured by the item "Was this conflict strictly a cultural issue?" on a scale from $1=$ not at all to $5=$ completely.

Perceived Individual Performance. The peacekeepers were asked to indicate for each statement (e.g. "I accomplished many worthwhile things in this job", "I dealt very effectively with the problems of the (local) people", "I felt I was positively influencing other people's lives through my work") the frequency that is most true for them on a scale from $0=$ never to $6=$ every day.

Satisfaction. This was measured by the item "I examine issues until I found a solution that really satisfied me and the other party" on a scale from $1=$ not at all to $5=$ completely. We also used the items "I was satisfied with the ending of this conflict" (scale is from $1=$ not at all to $5=$ completely) and multi-choice item "What were the consequences of this conflict?" with the following choices: "negative consequences for me personally", "positive consequences for me personally", "negative consequences for our mission", and "positive consequences for our mission" (scale from $1=$ not at all to $5=$ completely). Additionally, the respondents were asked an open-ended question, "How did the conflict end?" We will content analyze these text data and provide indications of peacekeepers' satisfaction.

Stress. The peacekeepers were asked to address their personal feelings and experiences during their latest mission. They indicated for each statement (e.g. "I felt emotionally drained from my work", "I felt used up at the end of the working day", "I felt fatigued when I got up in the morning and had to face another day on the job", "I felt burned out 
from my work", etc.) the frequency that is most true for them on a scale from $0=$ never to $6=$ every day.

\section{Results}

To be continued!!!

\section{Discussion}

Implications for peacekeeping in future conflict and post-conflict interventions. Our findings should help provide some insight for future studies in recognizing the uniqueness of the peacekeeping activities and in the design of occupation-specific intervention for reducing work stress.

To be continued!!! 


\section{References}

Amason, A., 1996. Distinguishing the effects of functional and dysfunctional conflict on strategic decision making: Resolving a paradox for top management teams. Academy of Management Journal, 39: 123-148.

Ancona, D. \& Caldwell, D. 1992. Bringing the boundary: External activity and performance in organizational teams. Administrative Science Quarterly, 37: 634-665.

Bacharach, S.B. \& Lawler, E.J. 1980. Power and politics in organizations. San Francisco: Jossey-Bass.

Baron, R. M., \& Kenny, D. A. 1986. The moderator - mediator variable distinction in social psychological research: Conceptual, strategic, and statistical considerations.

Journal of Personality and Social Psychology, 51: 1173-1182.

Byrne, D. 1971. The Attraction Paradigm. New York: Academic Press.

Caplow, T. 1956. A theory of coalitions in the triad. American Sociological Review, 21: 489-493.

Friedman, R., Tidd, S., Currall, S., \& Tsai, J. 2000. What goes around comes around: The impact of personal conflict style on work conflict and stress. The International Journal of Conflict Management, 11(1): 32-55.

Hogg, M., Turner, J. \& Davidson, B. 1990. Polarized norms and social frames of reference: A test of the self-categorization theory of group polarization. Basic and Applied Social Psychology, 11 (1): 77-100.

Jackson, S. 1992. Team composition in organizations. In S. Worchel, W. Wood, and J. Simpson (eds.), Group Process and Productivity: 1-12. London: Sage.

Jehn, K.A. 1995. A multimethod examination of the benefits and detriments of intragroup conflict. Administrative Science Quarterly, 40, 256-282.

Jehn, K.A. 1997. A qualitative analysis of conflict types and dimensions in organizational groups. Administrative Science Quarterly, 42: 520-557.

Jehn, K.A. \& Shah, P.P., 1997. Interpersonal Relationships and Task Performance: An Examination of Mediating Processes in Friendship and Acquaintance Groups. Journal of Personality and Social Psychology, 72 (4): 775-790

Jehn, K.A., Northcraft, G. \& Neale, M. 1999. Why Differences Make a Difference: A Field Study of Diversity, Conflict, and Performance in Workgroups. Administrative Science Quarterly, 44: 741-763.

Komorita, S.S. \& Kravitz, D.A. 1983. Coalition formation: A social psychological approach. In Paulus (Ed.), Basic group processes: 1979-203. New York: Springer-Verlag.

Lau, D. \& Murnighan, J.K. 1998. Demographic Diversity and Faultlines: The Compositional Dynamics of Organizational Groups. Academy of Management Review, 23(2): 325-340. 
Leeds, C. 2001. culture, conflict resolution, Peacekeeping training and the D mediator. Paper presented at the IACM Conference, Paris, 24-27 June.

Mack, R. and Snyder, R.S. 1957. The Analysis of Social Conflict - Toward an Overview and Synthesis. Journal of Conflict Resolution, 1, 212-248.

Motowidlo, S., Packard, J., \& Manning, M. 1986. Occupational stress: Its causes and consequences for job performance. Journal of Applied Psychology, 71: 618-629.

Murnighan, J.K. 1978. Models of coalition behavior: Game theoretic, social psychological and political perspectives. Psychological Bulletin, 85: 1130-1153.

O’Leary, B., \& McGarry, J. 1995. Regulating nations and ethnic communities. Chapter 11 in Breton, A. et all (Eds.), Nationalism and rationality. New York: Cambridge University Press.

Pelled, L., Eisenhard, K. \& Xin, K. 1999. Exploring the Black Box: An Analysis of Work Group Diversity, Conflict, and Performance. Administrative Science Quarterly, 44: 1-28.

Pool, J. 1976. Coalition formation in small groups with incomplete communication networks. Journal of Personality and Social Psychology, 34 (1): 82-91.

Scheider, B. 1983. An interactionist perspective on organizational effectiveness. In L. L. Cummings \& B. M. Staw (Eds.), Research on organizational behavior, Vol. 5, pp. 1-31. Greenwich, CT: JAI Press.

Tajfel, H. \& Turner, J.C. 1986. The social identity theory of intergroup behavior. In Worchel \& Austin (Eds.), Psychology of intergroup relations ( $2^{\text {nd }}$ ed., pp. 7-24). Chicago: Nelson-Hall.

Tinsley, C. \& Pillutla, M. 1998. Negotiating in the Unites States and Hong Kong. Journal of International Business Studies, 29 (4): 711-728.

UNICEF. 1986. Children in situation of armed conflict. New York: UNICEF (E/ICEF.CRP.2) 
Figure 1: Research Model

\begin{tabular}{|l|l|l|l|}
\hline Potential \\
Faultlines
\end{tabular}

